\title{
Correction to: Seismic Design of a Single Bored Tunnel: Longitudinal Deformations and Seismic Joints
}

\author{
J. Oh ${ }^{1} \cdot$ T. Moon ${ }^{2}$ (1)
}

Published online: 28 February 2018

(c) Springer-Verlag GmbH Austria, part of Springer Nature 2018

\section{Correction to: Rock Mechanics and Rock Engineering https://doi.org/10.1007/s00603-017-1366-0}

This paper, not properly checked by the authors when receiving the proofs, is in need of corrections as indicated below.

In the first paragraph of Section 3 "Geology and Dynamic Soil and Rock Properties", the first sentence was written as: "The geologic strata encountered during subsurface investigation are described in detail in the Geotechnical Design and Construction Considerations Report (PB 2010a)". It should be corrected as: "The overview of the geologic condition including physical and mechanical properties as well as tectonic-seismic setting are described in the Geotechnical Design and Construction Considerations Report (PB 2010a), and in Arioglu et al. (2016)".
The original article can be found online at https://doi.org/10.1007/ s00603-017-1366-0.

\section{T. Moon}

tmoon@hntb.com

1 School of Mining Engineering, UNSW Sydney, Sydney, NSW 2052, Australia

2 Geotechnical and Tunneling Division, HNTB, Empire State Building, 350 Fifth Avenue, 57th Floor, New York, NY 10118, USA
The corresponding reference is given below:

Arioglu B, Gokce HB, Malcioglu FS, Arioglu E (2016) TBM tunnel under the Bosphorous for the Istanbul Strait Road Crossing Project. Geomech Tunn 9(4):303-309.

The Acknowledgements, not given in the original publication, are as follows.

Acknowledgements The authors wish to acknowledge Yapi Merkezi and SK E\&C, who made this interesting and challenging project possible and provided the opportunity to work on it. Recognition is given to Dr. Jaw-Nan (Joe) Wang, who successfully supervised the seismic design team in Parsons Brinkerhoff, NY. Also appreciated are the many fruitful comments and suggestions by the chief editor, associate editor and the anonymous reviewers. 